\title{
Nasolabial Cyst: Clinical Presentation and Differential Diagnosis
}

\author{
Satya Narain
}

Received: 10 August 2010/ Accepted: 10 March 2011/Published online: 27 July 2011

(C) Association of Oral and Maxillofacial Surgeons of India 2011

\begin{abstract}
Nasolabial cyst also known as Klestadt's cyst is relatively rare soft tissue lesion of nasal alar region. It is nonodontogenic in origin and characterized by its extra osseous location. This paper documents clinical presentation, differential diagnosis and surgical management of nasolabial cyst in 25 years old woman.
\end{abstract}

Keywords Nasolabial $\cdot$ Soft tissue cyst $\cdot$ Nonodontogenic cyst

\section{Introduction}

Nasolabial cyst is a developmental nonodontogenic type of soft tissue cyst occurring in nasal alar region of midface. Since its original description by Zukerkandl in 1882, nasolabial cyst has been known by other names such as nasovestibular cyst, nasoglobular cyst and nasoalveolar cyst [1]. In 1953, Klestadt [2] studied about nasolabial cysts in depth after which lesion became named Klestadt's cyst. Thoma suggested the term nasoalveolar cyst, but it was Rao in 1951 that used the term nasolabial cyst.

There are two hypothesis regarding the pathogenesis of nasolabial cyst. According to first hypothesis, the cyst is derived from epithelial cells retained in the mesenchyme after fusion of medial and lateral nasal processes at approximately 4th week of intrauterine life. The second hypothesis suggests the persistence of epithelial remnants

S. Narain $(\bowtie)$

Department of Oral \& Maxillofacial Surgery, Dr. H.S. Judge

Institute of Dental Sciences \& Hospital, Panjab University,

Sector -25, Chandigarh, India

e-mail: satya.maxfac@gmail.com from the nasolacrimal duct extending between the lateral nasal process and maxillary prominence.

Nasolabial cysts are found most often in female adults in the fourth to fifth decade of life. Clinically the lesion presents as painless asymptomatic swelling in nasolabial region. Common clinical features include slowly growing painless mass which results in obliteration of nasolabial sulcus, nasal vestibule and maxillary labial sulcus. When palpated the lesion is soft and fluctuant in consistency. Patients generally report to clinician for the cosmetic reason or problem of nasal blockage.

Diagnosis is established by clinical findings. Nasolabial cysts do not present any finding on plain radiographs. Computed Tomography and Magnetic Resonance Imaging can reveal the extent and relation of lesion to surrounding structures [3-6]. Histopathologically the cyst is lined with pseudostratified columnar epithelium and occasionally a stratified squamous epithelium [1,7].

\section{Case Report}

A 25-year-old woman presented with chief complaint of non-painful lip swelling and nasal asymmetry. Swelling had been evident for approximately 4 years, over which time the swelling had been slowly growing. On examination there was a single diffuse swelling at left nasal alar region. There was obliteration of left nasolabial sulcus (Fig. 1a, b). On intranasal examination there was partial obliteration of anterior nasal vestibule on left side. Intraorally, there was fullness of maxillary labial vestibule contiguous to maxillary incisors and left canine. Overlying labial mucosa was normal in color (Fig. 2). On palpation the lesion was approximately $3 \times 4 \mathrm{~cm}$ in size, soft and cystic in consistency, fluctuant, mobile and nontender. 

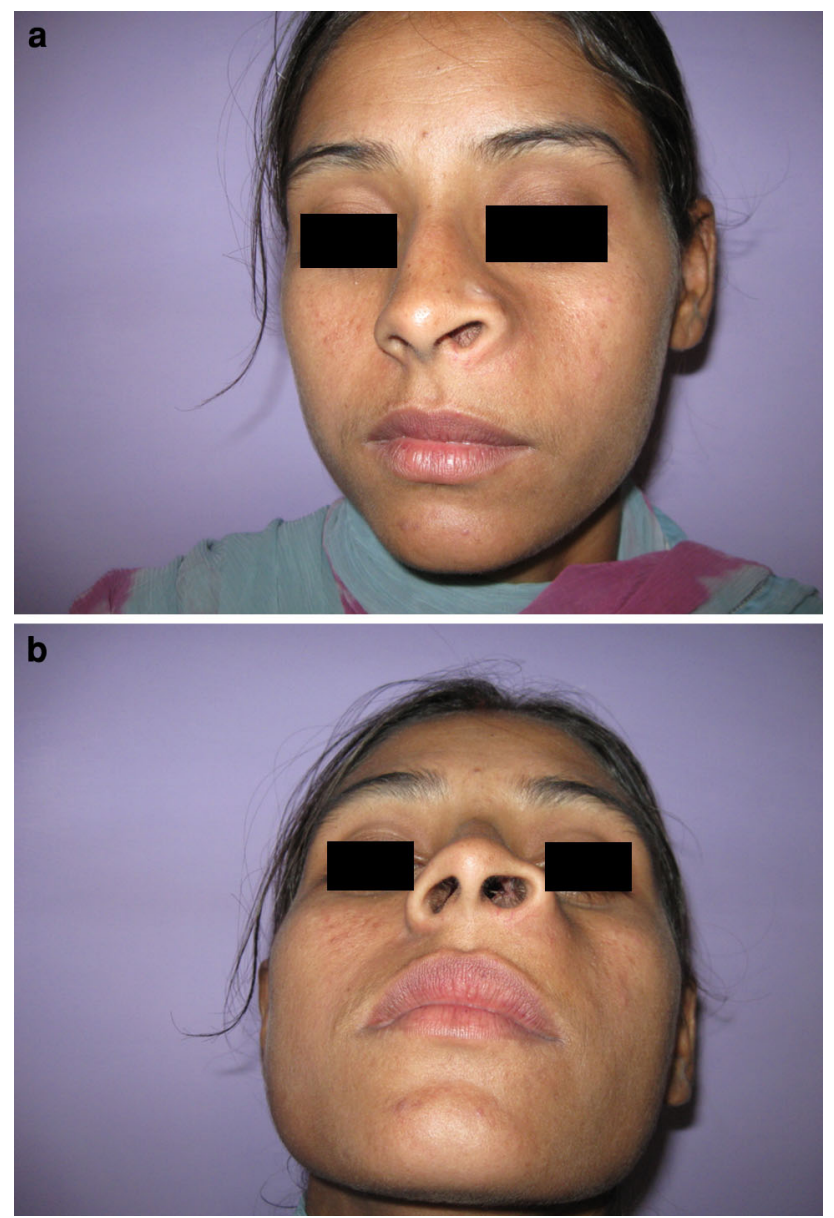

Fig. 1 a Preoperative frontal photograph of a patient with nasolabial cyst under the left alar base of nose and the maxillary lip. Obliteration of left nasolabial sulcus is easily seen. b Preoperative inferior photograph of the patient. Asymmetry caused by the submucosal cystic mass is clearly evident under left alar base of nose and maxillary lip

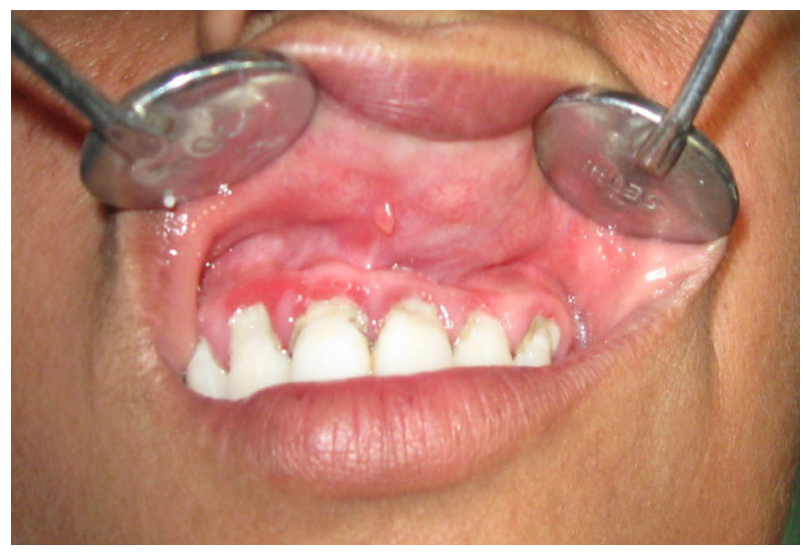

Fig. 2 Intraoral view of nasolabial cyst. The vestibule is distended by submucosal cystic mass

The associated teeth tested vital on electric pulp testing. Orthopantomogram and periapical radiograph of contiguous teeth showed normal bony architecture (Fig. 3). Fine needle aspiration revealed cystic fluid in swelling and microscopically few normal epithelial cells were present on smear. A working diagnosis of nasolabial cyst was made. Patient was advised contrast enhanced CT scan but the patient refused to undergo further investigation.

The lesion was removed under local anesthesia through transoral sublabial approach. A $5 \mathrm{~cm}$ long incision through labial mucosa was given and the lesion carefully dissected and separated from labial mucosa, underlying maxillary alveolus, overlying skin and nasal mucosa and removed in toto (Fig. 4). After curettage of contiguous hard and soft tissue, wound was closed primarily. Postoperative healing phase remained uneventful. Microscopic evaluation of excised specimen (Fig. 5) revealed a cystic structure lined with pseudostratified columnar epithelium (Fig. 6).

\section{Discussion}

Various lesions that should be considered in differential diagnosis of nasolabial cyst include odontogenic and nonodontogenic lesions that can occur in anterior maxilla or in soft tissues of alar labial region.

Radicular cyst arising from maxillary anterior teeth may extend into adjacent soft tissues, vitality test and presence of radiolucency in relation to apices of involved teeth can rule out this diagnosis.

Periapical abscess arising from maxillary anterior dentition is an inflammatory lesion. The classic signs and symptoms of inflammation and presence of a nonvital tooth make it different from nasolabial cyst.

Nasopalatine duct cyst should also be considered in differential diagnosis of nasolabial cyst. This cyst is intraosseous in location where as nasolabial cyst is exclusively found in soft tissues. Another difference is that nasopalatine duct cyst is found in anterior midpalatine region.

Odontogenic cyst such as dentigerous cyst and rarely odontogenic keratocyst may perforate the labial cortex and their presence in the soft tissue may mimic nasolabial cyst. Presence of radiolucency on the radiograph and their intraosseous location make them different from nasolabial cyst.

Benign soft tissue neoplasms such as schwannomas or neurofibromas and minor salivary gland tumors should also be considered in the differential diagnosis of nasolabial cyst. These lesions are distinguished from nasolabial cyst on the basis of their solid consistency and lack of enhancement. Presence of fluid level would be atypical in these lesions.

Dermoid and epidermoid cysts may arise in midnasal or laterally below nasal ala.These lesions are diagnosed in childhood whereas nasolabial cyst almost invariably 
Fig. 3 Both IOPA and OPG $X$ ray showing normal bony architecture and no abnormality
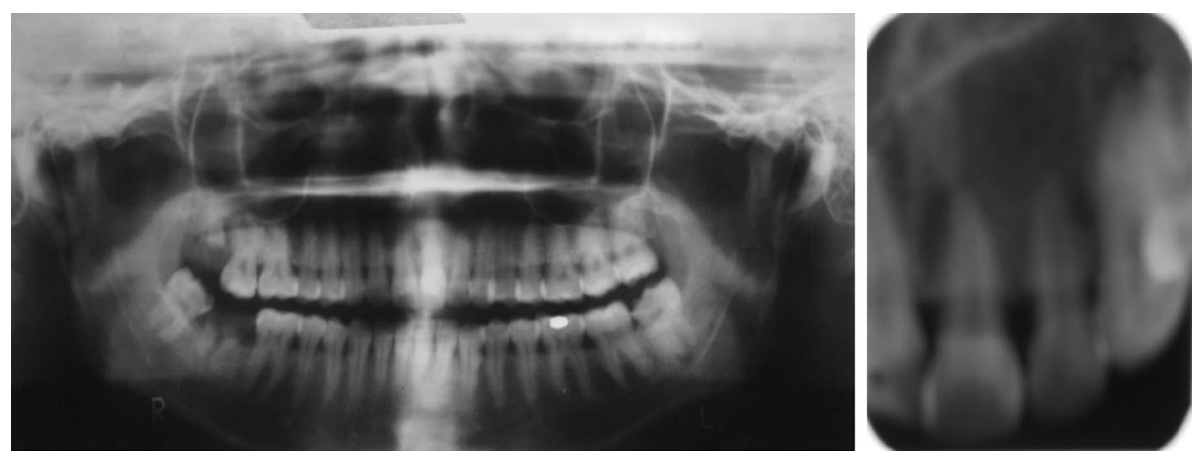

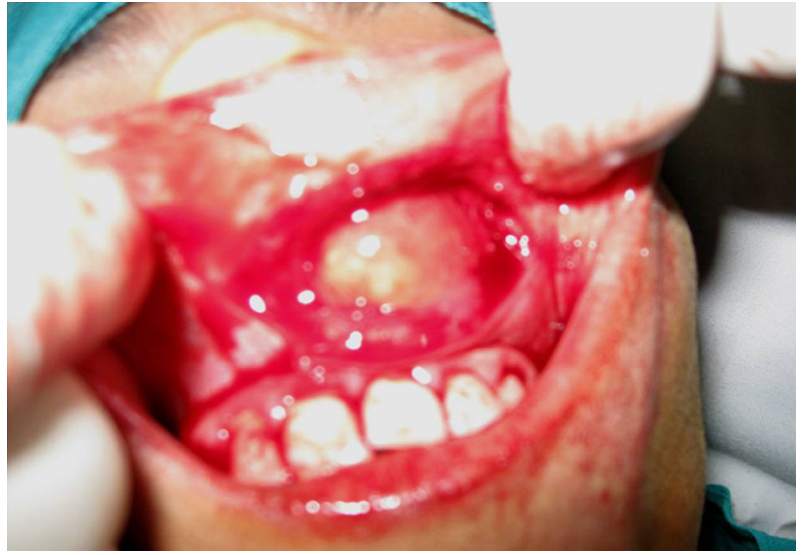

Fig. 4 Surgical exposure of the nasolabial cyst reveals the distended cystic mass and attachment to overlying tissue

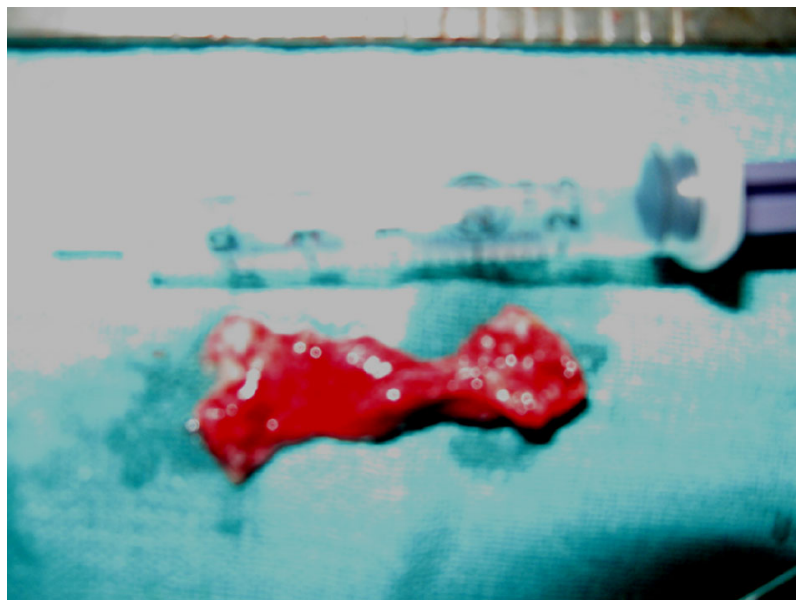

Fig. 5 Surgical specimen. The cystic mass measured $5 \times 3 \mathrm{~cm}$ in size

present in adults. A distinguishing feature of these very rare cysts may be their yellow hue, as opposed to normal pink or bluish coloration of nasolabial cyst.

Nasolabial cysts mostly occur in fourth decade of life. Women to men incidence ratio is $3: 1$. Bilateral presentation is present in $10 \%$ of cases [8]. Diagnosis requires correlation of the clinical and histological information $[9,10]$.

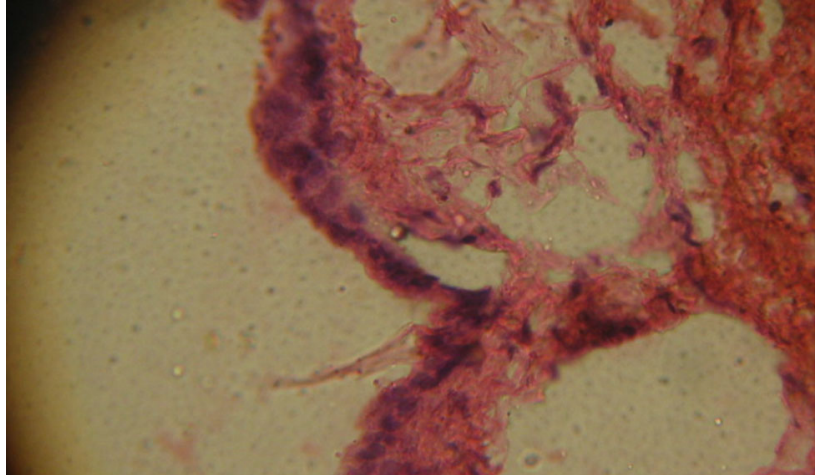

Fig. 6 Histopathological section show the cystic lining characterized by stratified squamous epithelium (Hematoxylin and Eosin stain, original magnification $\times 10$ )

Treatment of choice is conservative surgical excision. The prognosis is excellent and recurrence is rare.

\section{Conclusion}

This report has presented classic clinical features and histological findings of nasolabial cyst. This lesion should always be kept considered in the differential diagnosis of soft tissue swelling in nasal alar region. After conservative surgical excision, recurrence is rare.

\section{References}

1. el-Din K, el-Hamd AA (1999) Nasolabial cyst: a report of eight cases and review of literature. J laryngol Otol 113:747-749

2. Klestadt WD (1953) Nasal cysts and facial cleft theory. Ann Otol Rhinol Laryngol 62:84-92

3. Graamans K, Van Zanthen ME (1983) Nasolabial cyst: diagnosis mainly based on topography? Rhinology 21:239-248

4. Hashida T, Usui M (2000) CT Image of nasoalveolar cyst. Br J Oral Maxillofac Surg 38:83-84

5. Cure JK, Osguthorpe JD, Van Tassel P (1996) MR of nasolabial cysts. Am J Neuroradiol 17:585-588 
6. Aquilino RN, Bazzo VJ et al (2008) Nasolabial cyst: presentation of a clinical case with CT and MR Images. Rev Bras Otorhinolaryngol 74(3):467-471

7. Burtschi TA, Stout RA (1963) Bilateral nasoalveolar cysts. Oral Surg 16:271-275

8. Brown-Kelley A (1848) Cyst of floor of nose. J Laryngol Rhinol Otol 13:272-276
9. Adam A, Lovelock DT (1985) Nasolabial cyst. Oral Surg Oral Med Oral Pathol 60(1):118-119

10. Wesley RK, Scannel T, Nathan LE (1984) Nasolabial cyst: presentation of a case with review of the literature. J Oral Maxillofac Surg 42(3):188-192 